\title{
Prevalence of unknown thyroid disorders in a Sardinian cohort
}

\author{
Alessandro P Delitala, Maria Grazia Pilia ${ }^{1}$, Liana Ferreli ${ }^{1}$, Francesco Loi ${ }^{1}$, \\ Nicolò Curreli ${ }^{1}$, Lenuta Balaci ${ }^{1}$, David Schlessinger ${ }^{2}$ and Francesco Cucca ${ }^{1,2,3}$ \\ Department of Clinical and Experimental Medicine, University of Sassari, Viale San Pietro 8, 07100 Sassari, Italy, \\ ${ }^{1}$ Istituto di Ricerca Genetica e Biomedica (IRGB), Consiglio Nazionale delle Ricerche, c/o Cittadella Universitaria di \\ Monserrato, Cagliari, Italy, ${ }^{2}$ Laboratory of Genetics, National Institute on Aging, Baltimore, MD 21224, USA and \\ ${ }^{3}$ Department of Biochemical Science, University of Sassari, Sassari, Italy
}

\author{
Correspondence \\ should be addressed \\ to A P Delitala \\ Email \\ aledelitala@tiscali.it
}

\begin{abstract}
Objective: To assess thyroid function, the presence of thyroid antibodies, as well as the presence of goiter and/or nodules in subjects without a prior diagnosis of thyroid disorders, in a region with mild to moderate iodine deficiency. Design and methods: This cross-sectional study is based on data obtained from first and third visits of participants in the Sardinian survey. We performed two different analyses. In one, we assessed the prevalence of unknown thyroid dysfunctions among 6252 subjects who had a medical examination and blood collection for assays of thyrotropin, free thyroxine, and antibodies against thyroperoxidase (AbTPO) and against thyroglobulin (AbTG). In a second analysis, we evaluated the frequency of undiagnosed goiter and nodules among 3377 subjects who had a thyroid ultrasound scan. Subjects were excluded if they had a previous history of thyroid disorders or presence of goiter and/or nodules, or thyroid surgery, or if they were taking drugs that could impair thyroid function.

Results: We found a low prevalence of overt thyroid dysfunction (hyperthyroidism $0.4 \%$ and hypothyroidism $0.7 \%$ ). The rates of subclinical hypothyroidism and hyperthyroidism were 4.7 and $2.4 \%$ respectively. Almost $16 \%$ of participants were positive for at least one antibody and $5.2 \%$ for both AbTG and AbTPO. Nodules were detected in $17.4 \%$ of subjects and the prevalence of goiter was $22.1 \%$.
\end{abstract}

Conclusions: Undiagnosed biochemical thyroid dysfunctions, unknown nodules, and goiter were common in subjects living in a mild to moderate iodine-deficient area. In this community, thyroid disorders often go undetected and screening could be reasonable in subjects at a higher risk.

\section{Introduction}

Thyroid disorders are one of the most frequent pathologies found in the general population, but identifying thyroid disease can be clinically challenging because subclinical thyroid dysfunction and autoimmune thyroiditis are often asymptomatic and usually diagnosed biochemically. Abnormal thyroid function has important public health consequences. Suppressed thyroid stimulating hormone (TSH) levels have been associated with an increased risk of atrial fibrillation, premature atrial beats, and stroke, and all cause mortality $(1,2,3)$. In addition, suppressed TSH levels have been associated with a decreased bone density (4).
Moreover, overt hypothyroidism contributes to elevated serum LDL cholesterol levels and is a risk factor for coronary heart disease, heart failure, and atherosclerosis $(5,6)$. Some studies also suggest that this may also be true in patients with subclinical hypothyroidism (7). Most epidemiological surveys have reported the biochemical aspects of thyroid disorders, although with different results. The difficulties for determinations and their comparison arise from the variable definitions of disease state, the heterogeneity of the populations studied, the range of normality of biochemical parameters, and the sensitivity of thyroid 
function tests used. For example, the introduction of assays for serum TSH sensitive enough to distinguish between normal and low concentrations allowed the identification of subjects with subclinical hyperthyroidism. Additional variables include genetic $(8,9)$ and environmental factors, such as iodine intake $(10,11)$. Indeed, almost one-third of the world's population lives in areas of iodine deficiency (12), and the prevalence of goiter can be as high as $80 \%$. The introduction of ultrasonography in epidemiological studies has increased the diagnostic power to assess the presence of goiter and/or nodules in comparison with studies in which goiter was assessed by physical examination (13). In this study, a large cohort provided a unique opportunity to conduct a cross-sectional study of abnormal thyroid function and morphology. We assess both the prevalence of abnormal biochemical thyroid disease and the frequency of nodules and goiter in subjects without known thyroid abnormalities.

\section{Materials and methods}

The SardiNIA study investigates more than 300 genotypic and phenotypic aging-related traits in a longitudinal survey. The main features of this project have been described in more detail previously (14). All residents from four towns (Lanusei, Arzana, Ilbono, and Elini) in a valley in Sardinia (Italy) were invited to participate. Since November 2001, participants had visited and their blood samples analyzed about every 3 years, generating three complete surveys, and some new subjects were progressively enrolled to complete family units.

We performed two analyses. In one, we analyzed the frequency of biochemical thyroid disorders, including all subjects who had a medical examination at the first time in the first or third visit waves. (We did not include participants from the second survey because TSH was the only parameter checked at that visit.) We excluded all subjects with self-reported thyroid disease (i.e. Hashimoto's thyroiditis, hyperthyroidism, or hypothyroidism) and those taking drugs impairing thyroid function (levothyroxine, thyrostatics, amiodarone, and carbolithium). The final cohort included 6252 participants (female, $54.8 \%$ ) aged 14-102 years. A second analysis was performed to observe the prevalence of undiagnosed thyroid nodules and goiter. We assessed all subjects in whom thyroid ultrasound was carried out during the third visit wave. Subjects who reported thyroid nodules, goiter, or thyroid surgery were excluded, yielding a final sample of 3377 participants (female, 52.4\%). The iodine status at the time of evaluation was not assessed. However, the data on urinary iodine excretion of subjects living in this area was obtained from a study by Martino et al. (15), showing a mild to moderate iodine deficiency.

\section{Biochemical and hormone assays}

Blood venous samples were drawn between 0700 and $0800 \mathrm{~h}$ after an overnight fast. Serum samples were assayed for TSH, free thyroxine $\left(\mathrm{FT}_{4}\right)$, and antibodies against thyroperoxidase (AbTPO) and against thyroglobulin (AbTG) using an automated chemiluminescence assay system (Immulite 2000, Erlangen, Germany). The method is a two-site, solid-phase chemiluminescent immunometric assay. Normal values are as follows: $\mathrm{TSH}, 0.4-4.0 \mu \mathrm{IU} / \mathrm{ml} ; \mathrm{FT}_{4}, 0.89-1.76 \mathrm{ng} / \mathrm{dl}$; AbTPO, <35 IU/ml; and AbTG, < $40 \mathrm{IU} / \mathrm{ml}$.

Overt hypothyroidism was defined as a serum TSH level above the upper limit of the reference range and serum $\mathrm{FT}_{4}$ level below the lower limit of the reference range. Overt hyperthyroidism was defined as serum TSH levels below the lower limit of the reference range and serum $\mathrm{FT}_{4}$ level above the upper limit of the reference range. We defined subclinical thyroid dysfunction as serum $\mathrm{FT}_{4}$ levels in the normal reference range together with high serum TSH (subclinical hypothyroidism) or low serum TSH (subclinical hyperthyroidism) level.

\section{Thyroid ultrasound}

Conventional thyroid ultrasound was performed with a realtime instrument (ATL 3500 HDI machine with a linear transducer 5-12 MHz). Subjects were supine, with neck hyperextended. A nodule was defined as the presence of any distinct lesion within the thyroid gland detected by ultrasound, regardless of the echoic pattern. Subjects with nodules were divided into two categories: 'solitary nodule' if only one nodule was detected, and 'two or more nodules' (otherwise defined 'multiple'), if the ultrasound scan revealed the presence of at least two nodules. Thyroid volume was calculated according to the ellipsoid model (16). Goiter was

Table 1 Characteristics of subjects in the analyses. Data are expressed as median (interquartile range).

\begin{tabular}{|c|c|c|}
\hline & Biochemical analysis & Ultrasound analysis \\
\hline Subjects $(n)$ & 6252 & 3377 \\
\hline $\operatorname{Sex}(M / F)$ & $2826 / 3426$ & $1608 / 1769$ \\
\hline Age (year) & $41.7(28.8-57)$ & $45.8(34.4-59.4)$ \\
\hline $\mathrm{TSH}(\mu \mathrm{IU} / \mathrm{ml})$ & $1.61(1.05-2.32)$ & $2.37(1.12-2.37)$ \\
\hline $\mathrm{FT}_{4}(\mathrm{ng} / \mathrm{dl})$ & $1.27(1.14-1.4)$ & $1.39(1.12-1.39)$ \\
\hline
\end{tabular}

$\mathrm{n}$, absolute number; $\mathrm{TSH}$, thyrotropin; $\mathrm{FT}_{4}$, free thyroxine. 
Table 2 Distribution of thyroid status across different age groups. Data are presented as $n$ (\%).

\begin{tabular}{|c|c|c|}
\hline Thyroid status & $<40$ & $40-49$ \\
\hline Overt hypothyroidism & $10(0.3)$ & $11(1.0)$ \\
\hline Subclinical hypothyroidism & $161(5.5)$ & $51(4.6)$ \\
\hline Euthyroidism & $2721(92.9)$ & $1027(92.2)$ \\
\hline Subclinical hyperthyroidism & $27(0.9)$ & $22(2.0)$ \\
\hline Overt hyperthyroidism & $9(0.3)$ & $3(0.3)$ \\
\hline Total & $2928(100)$ & $1114(100)$ \\
\hline Any dysfunction ${ }^{a}$ & $207(7.0)$ & 87 (7.9) \\
\hline
\end{tabular}

apresence of any biochemical thyroid dysfunction (subclinical and overt).

defined as a thyroid volume exceeding $13 \mathrm{ml}$ in women and $18.1 \mathrm{ml}$ in men (17), regardless of the presence of nodules.

Each participant signed an informed consent form. All study methods were conducted according to the principles laid down in the Declaration of Helsinki and were approved by the governing Ethics Committee, ASL4.

\section{Statistical analysis}

Results are expressed as median and interquartile range. Statistical differences in frequencies were tested by the Fisher's exact test in Stata 12.0 for Macintosh. Significance was set at $P<0.05$.

\section{Results}

\section{Biochemical thyroid dysfunctions}

The baseline characteristics of the subjects are given in Table 1. Overt hypothyroidism and hyperthyroidism were diagnosed in $42(0.7 \%)$ and $23(0.4 \%)$ participants respectively. Subclinical hypothyroidism was found in 293 (4.7\%) subjects, whereas subclinical hyperthyroidism was detected in 152 (2.4\%) subjects. The prevalence of thyroid dysfunctions progressively increased with age, to reach a maximum of $13.9 \%$ in subjects older than 80 (Table 2). The distribution of AbTPO and AbTG across age groups is shown in Fig. 1. Table 3 displayed the frequency of AbTPO and AbTG across thyroid dysfunctions. The frequency of thyroid antibodies was higher in women than in men $(P<0.001)$, when considering the presence of at least one antibody (20.9 vs $9.9 \%$ ), when detected both together (6.9 vs $3.1 \%$ ), as shown in Table 4 . Among the whole sample studied, 1307 (20.9\%) participants had at least one biochemical thyroid disorder: 313 had hyper- or hypo-function of the gland without detectable thyroid antibodies, 797 showed only the positivity of at least one antibody, and 197 had a thyroid dysfunction associated with at least one circulating antibody.

\section{Thyroid nodules and goiter}

The second analysis included 3377 subjects in whom thyroid ultrasound was performed during the third survey. Among them, 588 (17.4\%) showed the presence of nodularity: 232 had a solitary nodule and 356 had at least two nodules. The presence of undiagnosed thyroid nodules progressively increased with aging, with the highest prevalence in subjects aged 80 years or older (31.6\%, Fig. 2). The presence of nodules (solitary or multiple) was associated with thyroid antibodies (AbTPO and/or AbTG) in 19\% of subjects. The overall prevalence of goiter was $22.1 \%$ and this progressively increased with aging, as reported in Fig. 2. It was observed in 748 subjects, among whom $99(13.2 \%)$ had a solitary nodule, 106

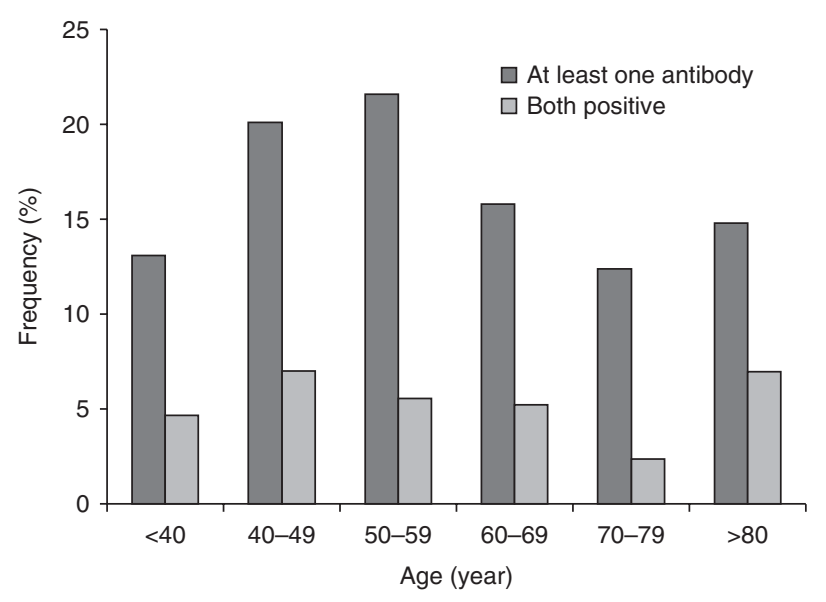

Figure 1

Frequency of antibodies against thyroglobulin and thyroperoxidase across different age groups. 
Table 3 Frequency of antibodies against thyroperoxidase and against thyroglobulin across thyroid status. Data are presented as $n(\%)$.

\begin{tabular}{l}
\hline Thyroid status \\
\hline Overt hypothyroidism \\
Subclinical hypothyroidism \\
Euthyroidism \\
Subclinical hyperthyroidism \\
Overt hyperthyroidism \\
Total
\end{tabular}

\begin{tabular}{c}
\hline Only AbTPO \\
\hline $29 / 42(69.1)$ \\
$117 / 293(39.9)$ \\
$533 / 5742(9.3)$ \\
$14 / 152(9.2)$ \\
$8 / 23(34.8)$ \\
$701 / 6252(11.2)$ \\
\hline
\end{tabular}

\begin{tabular}{c}
\hline Only AbTG \\
\hline $13 / 42(31.0)$ \\
$81 / 293(27.7)$ \\
$489 / 5742(8.5)$ \\
$21 / 152(13.8)$ \\
$11 / 23(47.8)$ \\
$615 / 6252(9.8)$
\end{tabular}

\begin{tabular}{c}
\hline AbTPO and/or AbTG \\
\hline $31 / 42(73.8)$ \\
$129 / 293(44.0)$ \\
$797 / 5742(13.9)$ \\
$26 / 152(17.1)$ \\
$11 / 23(47.8)$ \\
$994 / 6252(15.9)$ \\
\hline
\end{tabular}

\begin{tabular}{c}
\hline AbTPO and AbTG \\
\hline $11 / 42(26.2)$ \\
$69 / 293(23.5)$ \\
$225 / 5742(3.9)$ \\
$9 / 152(5.9)$ \\
$8 / 23(34.8)$ \\
$322 / 6252(5.2)$ \\
\hline
\end{tabular}

\begin{tabular}{r} 
No antibodies \\
\hline $11 / 42(26.2)$ \\
$164 / 293(56.0)$ \\
$4945 / 5742(86.1)$ \\
$126 / 152(82.9)$ \\
$12 / 23(52.2)$ \\
$5258 / 6252(84.1)$
\end{tabular}

AbTPO, antibodies against thyroperoxidase; AbTG, antibodies against thyroglobulin

(14.2\%) had multiple nodules, and 543 (72.6\%) did not show nodularity. Females had a higher frequency of nodularity than males $(P<0.001$, Table 5) (for solitary nodule, 8.0 vs 5.6\%; for multiple nodules, 11.2 vs $9.8 \%$ ), while the prevalence of goiter was increased in males (26.1 vs $18.5 \%, P<0.001$ ), as reported in Table 5 .

\section{Discussion}

Although thyroid dysfunction has multiple implications for public health, the magnitude of the problem is not completely known, nor is the relationship to other thyroid alterations well delineated. Our large population-based study in an area with mild to moderate iodine deficiency provides comprehensive data on the prevalence of unknown thyroid dysfunctions, autoimmune thyroid disorders, and unknown thyroid nodularity and goiter.

Overt hyperthyroidism was found in $0.4 \%(23 / 6252)$ of the sample. This finding is somewhat higher than those described in Norway (18) and in the Colorado Study (19), but similar to those reported by Volzke in Germany (20). The prevalence of unknown subclinical hyperthyroidism was $2.4 \%$. These findings were again lower than those reported in some studies (17), but higher than others (20, 21, 22, 23). Differences between studies may reflect different age ranges of cohorts and other environmental factors. Particularly important is the local iodine level. For example, a higher prevalence of hyperthyroidism due to an increased frequency of toxic nodular goiter has been documented in an iodine-deficient community (17), and subclinical hyperthyroidism was also more frequent in an iodine-deficient area compared with an iodine-replete area $(17,20,22)$. Our survey showed a prevalence of hyperthyroidism, which is somewhere between the prevalence reported in iodine-deficient areas and iodine-replete areas, and consistent with the mild to moderate iodine deficiency in this area. However, we cannot differentiate the type of hyperthyroidism because we did not assess antibodies against TSH receptor.

Table 4 Frequency of thyroid disorders stratified by sex. Data show the number of patients in each group, with percentages in parentheses. Data are presented as $\mathrm{n}(\%)$.

\begin{tabular}{|c|c|c|}
\hline Biochemical analysis & Female $(n=3426)$ & Male $(n=2826)$ \\
\hline Thyroid dysfunction & $335(9.8)$ & $175(6.2)$ \\
\hline Overt hypothyroidism & $30(0.9)$ & $12(0.4)$ \\
\hline Subclinical hypothyroidism & $198(5.8)$ & $95(3.4)$ \\
\hline Subclinical hyperthyroidism & $92(2.7)$ & $60(2.1)$ \\
\hline Overt hyperthyroidism & $15(0.4)$ & $8(0.3)$ \\
\hline \multicolumn{3}{|l|}{ Antibodies } \\
\hline Only AbTPO & $494(14.4)$ & $207(7.3)$ \\
\hline Only AbTG & 456 (13.3) & $159(5.6)$ \\
\hline AbTPO and/or AbTG & $715(20.9)$ & $279(9.9)$ \\
\hline AbTPO and AbTG & $235(6.9)$ & $87(3.1)$ \\
\hline Any biochemical thyroid disorders ${ }^{d}$ & $895(26.1)$ & $412(14.6)$ \\
\hline
\end{tabular}

\begin{tabular}{|c|c|}
\hline Total $(n=6252)$ & $P$ value $^{a}$ \\
\hline $510(8.2)$ & $<0.001$ \\
\hline $42(0.7)$ & $0.016^{b}$ \\
\hline $293(4.7)$ & $<0.001^{c}$ \\
\hline $152(2.4)$ & NS \\
\hline $23(0.4)$ & NS \\
\hline 701 (11.2) & $<0.001$ \\
\hline $615(9.8)$ & $<0.001$ \\
\hline 994 (15.9) & $<0.001$ \\
\hline $332(5.2)$ & $<0.001$ \\
\hline 1307 (20.9) & $<0.001$ \\
\hline
\end{tabular}

AbTPO, antibodies against thyroperoxidase; AbTG, antibodies against thyroglobulin

aWomen vs men (Fisher's exact test).

bvert hypothyroidism vs euthyroidism.

'Subclinical hypothyroidism vs euthyroidism.

${ }^{\mathrm{d}}$ Presence of thyroid dysfunction and/or presence of at least one thyroid antibody. 


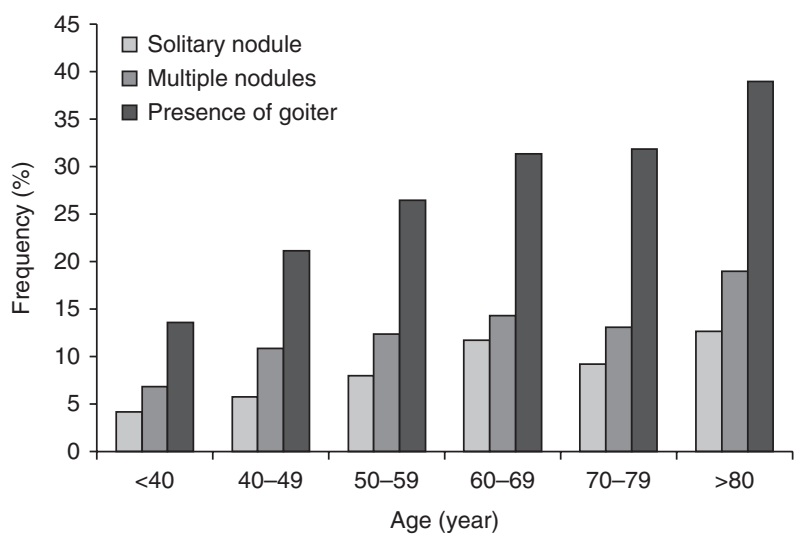

Figure 2

Prevalence of nodules and goiter across age groups.

The prevalence of overt hypothyroidism was $0.7 \%$ (42/6252), with a higher frequency in females $(71.4 \%)$ than in males (28.6\%). This prevalence is similar to that reported by Volzke et al. (20) but higher than that reported by Aghini-Lombardi et al. (17) in another survey in Italy and by Lucas et al. (21) in Spain. Moreover, we found unknown subclinical hypothyroidism in $4.7 \%$ of subjects, which is substantially higher than that reported previously.

In this study, the prevalence of thyroid antibodies (AbTPO, AbTG, or both) was $15.9 \%$, which is higher than that reported in previous studies. However, whether or not iodine intake influences the development of thyroid autoimmunity remains controversial. Indeed, both low and high iodine intake have been associated with an increased tendency toward thyroid autoimmune abnormalities $(10,24,25)$. According to some authors, the development of goiter due to iodine deficiency might overexpose the immune system to thyroid antigens, leading to immune reactions $(26,27)$. Assuming that iodine intake might interfere with the thyroid autoimmune process, only genetically predisposed subjects would present the disease (28). In keeping with this hypothesis, our data are consistent with a very high incidence of autoimmune diseases such as chronic autoimmune thyroiditis, type 1 diabetes mellitus, and multiple sclerosis in the Sardinian population (29). The prevalence of thyroid dysfunctions linked to the presence of AbTPO and/or AbTG ranged from $73.8 \%$ in subjects with overt hypothyroidism to $17.1 \%$ in those with subclinical hyperthyroidism (Table 3). Moreover, 13.9\% of subjects with euthyroidism had circulating thyroid antibodies. These data are in line with previous findings that overt and subclinical hypothyroidism generally are autoimmune, whereas subclinical hyperthyroidism is usually related to multinodular goiter, with relatively frequent detection of serum thyroid antibodies, especially in goitrous females $(17,26,30,31)$ and in older subjects, as confirmed in our analysis.

The second analysis included 3377 patients who underwent thyroid ultrasound. We found 588 subjects (17.4\%) with unknown thyroid nodules, 232 with solitary nodules, and 356 with at least two nodules. These findings are comparable to those reported by other authors (20). The prevalence of thyroid nodules increased with age up to 80 years and above (31.6\%).

Age and sex distributions were similar to those observed in previous reports in moderate iodine-deficient areas, with a progressive increased prevalence of goiter in older subjects, though the prevalence of goiter was rather lower than that reported by Martino et al. (15) in the same geographic area. Different methods of estimation may account for this difference.

One exclusion criterion was self-reported patient data for previous diagnosis of thyroid disease and/or medications. Hence, all the data should be analyzed with some reservations about possible undercounting, but the results of our analysis are consistent with previous reports.

A major finding of our study was a $20.9 \%(1307 / 6252)$ prevalence of undiagnosed biochemical abnormalities of the thyroid gland. In this group, 313 subjects (23.9\%) had thyroid dysfunction, and the positivity of thyroid antibodies was found in 797 subjects (61\%), whereas thyroid dysfunction together with circulating antibodies were found in 197 participants (15.1\%). Our study indicates that the prevalence of thyroid dysfunction and/or abnormal thyroid anatomy is rather frequent in an unselected population living in this mild to moderate iodine-deficient region. Although in this study the demographic characteristics of the population studied may not be completely generalizable, we provide

Table 5 Frequency of goiter and nodules stratified by sex. Data shows the number of patients in each group, with percentages in parentheses.

\begin{tabular}{|c|c|c|c|c|}
\hline $\begin{array}{l}\text { Ultrasound } \\
\text { analysis }\end{array}$ & $\begin{array}{l}\text { Female } \\
(n=1769)\end{array}$ & $\begin{array}{c}\text { Male } \\
(n=1608)\end{array}$ & $\begin{array}{c}\text { Total } \\
(n=3377)\end{array}$ & $P$ value $^{a}$ \\
\hline Goiter & $328(18.5)$ & $420(26.1)$ & $748(22.1)$ & $<0.001$ \\
\hline Nodules & 341 (19.2) & 247 (15.4) & 588 (17.4) & 0.002 \\
\hline Solitary nodule & $142(8.0)$ & $90(5.6)$ & 232 (6.9) & 0.002 \\
\hline $\begin{array}{l}\text { Two or more } \\
\text { nodules }\end{array}$ & $199(11.2)$ & 157 (9.8) & 356 (10.5) & NS \\
\hline
\end{tabular}

${ }^{\mathrm{a}}$ Female vs men (Fisher's exact test). 
additional epidemiological data on the undiagnosed thyroid disorders, confirming the magnitude of thyroid dysfunction in this area.

The large number of patients with abnormal thyroid parameters and/or thyroid nodules, coupled with the wellestablished gradual progression of thyroid dysfunction, indicates the potential benefit from testing for abnormal thyroid function, at least in these geographic areas.

\section{Declaration of interest}

The authors declare that there is no conflict of interest that could be perceived as prejudicing the impartiality of the research reported.

\section{Funding}

This work was supported by the National Institute on Aging (contract NO1-AG-1-2109).

\section{References}

1 Sawin CT, Geller A, Wolf PA, Belanger AJ, Baker E, Bacharach P, Wilson P, Benjamin EJ \& D'Agostino RB. Low serum thyrotropin concentrations as a risk factor for atrial fibrillation in older persons. New England Journal of Medicine 1994331 1249-1252. (doi:10.1056/ NEJM199411103311901)

2 Sheu JJ, Kang JH, Lin HC \& Lin HC. Hyperthyroidism and risk of ischemic stroke in young adults: a 5-year follow-up study. Stroke 2010 41 961-966. (doi:10.1161/STROKEAHA.109.577742)

3 Parle JV, Maisonneuve P, Sheppard MC, Boyle P \& Franklyn JA. Prediction of all-cause and cardiovascular mortality in elderly people from one low serum thyrotropin result: a 10-year cohort study. Lancet 2001358 861-865. (doi:10.1016/S0140-6736(01)06067-6)

4 Ross DS, Neer RM, Ridgway EC \& Daniels GH. Subclinical hyperthyroidism and reduced bone density as a possible result of prolonged suppression of the pituitary-thyroid axis with L-thyroxine. American Journal of Medicine 198782 1167-1170. (doi:10.1016/00029343(87)90219-1)

5 McQuade C, Skugor M, Brennan DM, Hoar B, Stevenson C \& Hoogwerf BJ. Hypothyroidism and moderate subclinical hypothyroidism are associated with increased all-cause mortality independent of coronary heart disease risk factors: a PreCIS database study. Thyroid 201121 837-843. (doi:10.1089/ thy.2010.0298)

6 Cappola AR \& Ladenson PW. Hypothyroidism and atherosclerosis. Journal of Clinical Endocrinology and Metabolism 200388 2438-2444. (doi:10.1210/jc.2003-030398)

7 Rodondi N, Aujesky D, Vittinghoff E, Cornuz J \& Bauer DC. Subclinical hypothyroidism and the risk of coronary heart disease: a meta-analysis. American Journal of Medicine 2006119 541-551. (doi:10.1016/j.amjmed. 2005.09.028)

8 Teumer A, Rawal R, Homuth G, Ernst F, Heier M, Evert M, Dombrowski F, Völker U, Nauck M, Radke D et al. Genome-wide association study identifies four genetic loci associated with thyroid volume and goiter risk. American Journal of Human Genetics 201188 664-673. (doi:10.1016/j.ajhg.2011.04.015)

9 Tomer Y. Genetic susceptibility to autoimmune thyroid disease: past, present, and future. Thyroid 201020 715-725. (doi:10.1089/ thy.2010.1644)
10 Laurberg P, Cerqueira C, Ovesen L, Rasmussen LB, Perrild H, Andersen S, Pedersen IB \& Carlé A. Iodine intake as a determinant of thyroid disorders in populations. Best Practice \& Research. Clinical Endocrinology \& Metabolism 201024 13-27. (doi:10.1016/ j.beem.2009.08.013)

11 Knudsen N, Laurberg P, Perrild H, Bülow I, Ovesen L \& Jørgensen T. Risk factors for goiter and thyroid nodules. Thyroid 200212 879-888. (doi:10.1089/105072502761016502)

12 Zimmermann MB. Iodine deficiency. Endocrine Reviews 200930 376-408. (doi:10.1210/er.2009-0011)

13 Vanderpump MP. The epidemiology of thyroid disease. British Medical Bulletin 201199 39-51. (doi:10.1093/bmb/ldr030)

14 Pilia G, Chen WM, Scuteri A, Orrú M, Albai G, Dei M, Lai S, Usala G, Lai M, Loi $P$ et al. Heritability of cardiovascular and personality traits in 6,148 Sardinians. PLoS Genetics 20062 e132. (doi:10.1371/journal. pgen.0020132)

15 Martino E, Loviselli A, Velluzzi F, Murtas ML, Carta M, Lampis M, Murru R, Mastinu A, Arba ML, Sica V et al. Endemic goiter and thyroid function in central-southern Sardinia. Report on an extensive epidemiological survey. Journal of Endocrinological Investigation 199417 653-657. (doi:10.1007/BF03349681)

16 Brunn J, Blocjk U, Ruf J, Bos I, Kunze WP \& Scriba PC. Volumetrie der schilddrusenlappen mittels real-time-sonographie. Deutsche Medizinische Wochenschrift 1993287 1206-1207.

17 Aghini-Lombardi F, Antonangeli L, Martino E, Vitti P, Maccherini D, Leoli F, Rago T, Grasso L, Valeriano R, Balestrieri A et al. The spectrum of thyroid disorders in an iodine-deficient community: the Pescopagano survey. Journal of Clinical Endocrinology and Metabolism 199984 561-566.

18 Bjoro T, Holmen J, Krüger O, Midthjell K, Hunstad K, Schreiner T, Sandnes L \& Brochmann H. Prevalence of thyroid disease, thyroid dysfunction and thyroid peroxidase antibodies in a large, unselected population. The Health Study of Nord-Trondelag (HUNT). European Journal of Endocrinology 2000143 639-647. (doi:10.1530/eje.0. 1430639)

19 Canaris GJ, Manowitz NR, Mayor G \& Ridgway EC. The Colorado thyroid disease prevalence study. Archives of Internal Medicine 2000160 526-534. (doi:10.1001/archinte.160.4.526)

20 Völzke H, Lüdemann J, Robinson DM, Spieker KW, Schwahn C, Kramer A, John U \& Meng W. The prevalence of undiagnosed thyroid disorders in a previously iodine-deficient area. Thyroid $2003 \mathbf{1 3}$ 803-810. (doi:10.1089/105072503768499680)

21 Lucas A, Julián MT, Cantón A, Castell C, Casamitjana R, Martínez-Cáceres EM \& Granada ML. Undiagnosed thyroid dysfunction, thyroid antibodies, and iodine excretion in a Mediterranean population. Endocrine 201038 391-396. (doi:10.1007/s12020010-9397-2)

22 Knudsen N, Bülow I, Laurberg P, Ovesen L, Perrild H \& Jørgensen T. Low socio-economic status and familial occurrence of goitre are associated with a high prevalence of goitre. European Journal of Epidemiology 2003 18 175-181. (doi:10.1023/A:1023001400945)

23 O'Leary PC, Feddema PH, Michelangeli VP, Leedman PJ, Chew GT, Knuiman M, Kaye J \& Walsh JP. Investigations of thyroid hormones and antibodies based on a community health survey: the Busselton thyroid study. Clinical Endocrinology 200664 97-104. (doi:10.1111/ j.1365-2265.2005.02424.x)

24 Konno N, Yuri K, Taguchi H, Miura K, Taguchi S, Hagiwara K \& Murakami S. Screening for thyroid diseases in an iodine sufficient area with sensitive thyrotrophin assays, and serum thyroid autoantibody and urinary iodide determinations. Clinical Endocrinology 199338 273-281. (doi:10.1111/j.1365-2265.1993.tb01006.x)

25 Alsayed A, Gad AM, Abdel-Baset H, Abdel-Fattah A, Ahmed A \& Azab A. Excess urinary iodine is associated with autoimmune subclinical hypothyroidism among Egyptian women. Endocrine Journal 200855 601-605. (doi:10.1507/endocrj.K07E-165) 
26 Fenzi GF, Giani C, Ceccarelli P, Bartalena L, Macchia E, Aghini-Lombardi F, Vitti P, Lari R, Ceccarelli C, Baschieri L et al. Role of autoimmune and familial factors in goiter prevalence. Studies performed in a moderately endemic area. Journal of Endocrinological Investigation 19869 161-164. (doi:10.1007/ BF03348088)

27 Costa A, de Filippis V, Balsamo A, Ravarino N, Testori O, Torchio B, Valmaggia P \& Zoppetti G. Serum autoantibodies and thyroid lymphocytic infiltration in endemic goitre. Clinical and Experimental Immunology 198456 143-148.

28 Tomer Y \& Davies TF. Searching for the autoimmune thyroid disease susceptibility genes: from gene mapping to gene function. Endocrine Reviews 200324 694-717. (doi:10.1210/er.2002-0030)
29 Sardu C, Cocco E, Mereu A, Massa R, Cuccu A, Marrosu MG \& Contu P. Population based study of 12 autoimmune diseases in Sardinia, Italy: prevalence and comorbidity. PLoS ONE 20127 e32487. (doi:10.1371/ journal.pone.0032487)

30 Mariotti S, Sansoni P, Barbesino G, Caturegli P, Monti D, Cossarizza A, Giacomelli T, Passeri G, Fagiolo U, Pinchera A et al. Thyroid and other organ-specific autoantibodies in healthy centenarians. Lancet 1992339 1506-1508. (doi:10.1016/0140-6736(92)91265-A)

31 Laurberg P, Pedersen KM, Hreidarsson A, Sigfusson N, Iversen E \& Knudsen PR. Iodine intake and the pattern of thyroid disorders: a comparative epidemiological study of thyroid abnormalities in the elderly in Iceland and in Jutland, Denmark. Journal of Clinical Endocrinology and Metabolism 199883 765-769. (doi:10.1210/jcem.83.3.4624)

Received 4 March 2014

Revised version received 18 April 2014

Accepted 30 April 2014 